\title{
Métodos móveis
}

Monika Büscher ${ }^{\star}$ e Leticia Veloso**

A realidade é movimento. BERGSON, [1919] 1960

Introdução: Por que "métodos móveis"?

Neste artigo, procuramos discutir a noção, aplicação e potencialidades dos chamados métodos móveis. Em vez de oferecer, aqui, um "manual de pesquisa" que ensine o "como fazer" dos métodos móveis, optamos por apresentar e discutir algumas pesquisas que consideramos emblemáticas por terem, em nossa avaliação, conseguido avançar de maneiras criativas, produtivas e significativas esse uso "móvel" das metodologias. A expressão "métodos móveis" se refere, em linhas gerais, aos esforços daqueles pesquisadores que, trabalhando principalmente dentro do chamado "novo paradigma das mobilidades" (Sheller e Urry, 2006), vêm desenvolvendo novos usos metodológicos para estudar as mobilidades naquilo que elas têm de mais específico - o movimento. Mais especificamente, ao incorporar as mobilidades aos métodos de pesquisa, busca-se avançar na compreensão de alguns dos traços característicos da vida contemporânea, tais como o fato de nossos sistemas de transporte, manufatura e energia ainda dependerem de combustíveis fósseis, o desenraizamento e consequentes fluxos de milhões de pessoas através de fronteiras reais e imaginadas, os fluxos e circulações quase invisíveis das finanças, a sedução

* Lancaster University (Reino Unido).

** Universidade Federal Fluminense - UFF.

1. Ao longo do artigo, utilizamos vários conceitos que vêm sendo trabalhados por autores que escrevem na língua inglesa, aqui traduzidos por Leticia Veloso. 
imaginada do turismo e suas relações com economias políticas diversas, ou os jogos de presença e ausência engendrados pelas comunicações digitais.

Não por coincidência, já que esses processos estão, de uma forma ou de outra, ligados às tecnologias digitais, muitos dos chamados métodos móveis priorizam tais tecnologias; por exemplo, no uso de tablets ou celulares como único dispositivo de produção e armazenamento de anotações de campo, ou de câmeras fotográficas ou de vídeo presas aos corpos dos pesquisadores. Também não por coincidência, vários desses métodos demandam dos pesquisadores "mover-se junto, estar junto, sentir junto" com os sujeitos e objetos pesquisados (Merriman, 2013) - afinal, estão sendo pesquisados movimento e mobilidade.

Esta é, certamente, uma maneira de se conceber um "método móvel”: técnicas, métodos e metodologias que permitam documentar, acompanhar (seguir) e compreender as diferentes mobilidades abarcadas pelo "novo paradigma" - mobilidades de pessoas, de coisas e de ideias (Sheller e Urry, 2006). Em algumas situações e em alguns tipos de pesquisa, entender uma forma particular de "mobilidade" pode realmente depender do uso de dispositivos tecnológicos como câmeras, gravadores, computadores, GPS etc., que ajudem o pesquisador a fazer e refazer determinados movimentos (como os de automóveis, motocicletas, bicicletas e pessoas pelas ruas de uma cidade, passageiros nos transportes públicos, logs de passageiros em aviões comerciais etc.).

Mas não é necessário pressupor nem que, nesses métodos, a pesquisa deva apenas se voltar para aqueles sujeitos e objetos que, por sua própria natureza, estão sempre em movimento, nem que toda a pesquisa sobre tais sujeitos e objetos precise ser realizada enquanto sujeitos e/ou objetos estão se movendo (Merriman, 2013). Pelo contrário, é importante não confundir "as mobilidades" como objeto de pesquisa com "a mobilidade" como metodologia de pesquisa (Ibidem): os métodos de que tratamos aqui não são "móveis” apenas porque servem para coletar dados sobre movimento; eles também são “móveis" porque nos ajudam a compreender as mobilidades em suas várias manifestações.

Um artigo de Mol e Mesman (1996, pp. 422-423) de mais de vinte anos atrás já havia discutido os riscos de se "fetichizar" a ideia de movimento presumindo, como único recurso metodológico, a necessidade de o pesquisador seguir, fisicamente, seu objeto de pesquisa por onde quer que ele passe: afinal, o que deveria o pesquisador fazer caso esse acompanhamento constante se mostrasse inviável? Paralisar a pesquisa? Um estudo realizado por Mesman e relatado no artigo (Ibidem) abordou essas dificuldades. Sua proposta inicial era acompanhar, fisicamente, os fluxos de objetos e informação numa unidade hospitalar neonatal "andando junto" com médicos, enfermeiras e objetos. Tal “andar junto”, porém, se revelou impraticável: por um lado, 
os médicos e enfermeiras se movimentavam rápida, incansável e incessantemente, ao longo de todas as horas de todos os dias, num ritmo que a pesquisadora não conseguia acompanhar; e, por outro, também não se podia "andar junto", fisicamente, dos objetos dos quais tratava a pesquisa - por exemplo, os minúsculos tubos utilizados na alimentação dos bebês - pois, pergunta ela, como poderia um corpo humano adulto "seguir o movimento" de objetos tão pequenos (Ibidem)? Mover-se fisicamente com os sujeitos e objetos da pesquisa pode ser muito difícil, se não impossível, quando os mesmos são pequenos ou grandes demais, rápidos ou lentos demais, complexos ou imateriais demais.

Mesmo assim, as possibilidades analíticas sugeridas pelo "novo paradigma das mobilidades" continuam estimulando e desafiando pesquisadores a aproximar movimento e método. Afinal, não se pode esquecer que a busca por métodos mais móveis e mais apropriados a novos temas e interesses de pesquisa é parte integrante de um paradigma que, no dizer de autores como Sheller e Urry (2006), entende o mundo de modo transdisciplinar e parte do princípio de que o social e o material, seus ritmos, histórias e futuros, são produzidos, fundamentalmente, por e através de (a) movimento, (b) movimento "impedido" (ou "bloqueado" ou "freado") e (c) não movimento ("calmaria").

Ou seja, o foco não são só pessoas, coisas e ideias que se movimentam, mas o movimento em si como elemento fundador da vida social. Em outras palavras, esse paradigma se constrói exatamente em torno de uma apreciação profunda do fato de que, sim, "a realidade é movimento" (Bergson, [1919] 1960, p. 319). Assim, o giro móvel reconhece e parte do pressuposto de que há uma "realidade" cuja natureza é sempre emergente e na qual as coisas, ideias e pessoas estão sempre em fluxo. Em outras palavras, tanto nesse paradigma quanto em outras concepções que enfatizam as processualidades e a construção sociopolítico-cultural dos processos que afetam a vida humana - como as teorias feministas, a teoria ator-rede, a teoria não representacional, a etnometodologia, as filosofias processuais e os estudos sociais da ciência e da tecnologia -, trabalha-se com a noção de que os fenômenos sociais e materiais são sempre produzidos e tornados duráveis pelas, nas, e através das interações entre diferentes agências que podem ser humanas e/ou não humanas (Sheller e Urry, 2006; Hannam et al., 2006).

Apesar desse suporte teórico e do continuado ímpeto experimentado pelas pesquisas em mobilidades que se apropriam desse paradigma, Sheller (2015) argumenta que a construção de metodologias adequadas, e em particular de métodos realmente móveis, criativos e que permitam pesquisa "em tempo real" sobre fenômenos tão complexos e que se delineiam em escalas tão diferentes, ainda enfrenta uma dificuldade básica: o fato, quase desanimador, de que tudo aquilo que é realmente 
móvel - o que, para Bergson, se aplica a toda e qualquer realidade ([1919] 1960, p. 317) -, justamente por estar sempre se movendo, acaba por definição "escapa[ndo] às perseguições da ciência”.

Gostaríamos de sugerir, porém, que tal dificuldade talvez advenha menos de uma impossibilidade inata de se conseguir capturar, científica e analiticamente, aquilo que é móvel, e mais de uma interpretação por demais estreita do que exatamente seriam, ou poderiam ser, os tais métodos móveis. Parece-nos, enfim, que uma tal interpretação restrita acerca das próprias possibilidades desse tipo de enfoque é o que está limitando e, em alguns casos até freando, as potencialidades analíticas que conseguimos buscar e encontrar através da pesquisa em mobilidades (Merriman, 2013).

Em outras palavras, as dificuldades não seriam inerentes aos métodos, nem às pesquisas, nem às realidades pesquisadas em si mesmas, mas surgiriam como resultado de uma relativa miopia criativa de alguns pesquisadores que ainda relutam em expandir seus horizontes e enxergar como exatamente devemos e podemos pesquisar as diferentes mobilidades que nos atraem a atenção, desafiando nossa compreensão. Por outro lado, já há vários pesquisadores e pesquisadoras trilhando caminhos mais móveis e mais transdisciplinares, que conduzem a pesquisas mais complexas. A seguir, discutiremos alguns desses exemplos, visando a contribuir exatamente para essa expansão de nossos horizontes de pesquisa (em mobilidades). Agrupamos os exemplos discutidos de acordo com os tipos de movimento e mobilidades enfocados: (1) mover-se e tornar-se, (2) mover-se e o movimento, (3) mover-se e comover-se, e (4) mover-se por impulso. Em todos os casos, procuramos demonstrar como, nos estudos aqui relacionados, o ato de se mover, como método e metodologia, seja figurada ou literalmente, pode ajudar a enfrentar as imobilidades (forçadas, reais ou imaginadas) por meio de novas possibilidades analíticas e políticas.

\section{Mover-se e tornar-se}

Pesquisadores que se movem junto ou em torno de seus objetos e sujeitos de pesquisa podem até "priorizar o 'estar lá" [...] como modo de compreender os fenômenos" estudados (Fincham et al., 2010, p. 171), mas isso não precisa ser exagerado a ponto de se concentrarem os esforços apenas em encontrar os modos mais "autênticos" de "trazer os dados de volta" para que os pesquisadores possam, à distância de seus objetos de pesquisa, devidamente trabalhar, analisar, quantificar, qualificar, depurar, "limpar" e, por fim, preparar os dados para publicação e, portanto, os olhos de outrem. Pelo contrário, queremos sugerir que tal priorização do movimento, do "estar lä" (ou "estar junto") e do ir e voltar pode ser pensada como uma maneira de se alcançar uma compreensão muito mais aprofundada de como exatamente os "lugares, espaços e 
subjetividades são constituídos através do movimento"; nesses casos, o mover-se como método pode incluir, por exemplo, etnografias sensoriais, experimentar e praticar, reflexivamente, formas de movimento juntamente com outros, e encontrar novas formas de articulação do que é móvel e da própria mobilidade dentro de um encontro de pesquisa verdadeiramente colaborativo (Brown e Spinney, 2009, p. 130). Tal estratégia metodológica, por sua vez, não precisaria incluir o ato de o pesquisador ou a pesquisadora "andar junto", fisicamente, com os participantes da pesquisa.

Laurier (2010) mostra como, do ponto de vista do/a pesquisador/a, o ato de "estar lá" sem o estar fisicamente - ou seja, "estando lá" indiretamente - pode ser um recurso metodológico válido. O que este autor produziu, como metodologia, foi bastante interessante: buscando compreender o que acontece nas viagens cotidianas de automóvel, do ponto de vista não do motorista, mas especialmente do passageiro (ou "carona”), o pesquisador convidou os participantes de sua pesquisa a documentarem suas viagens diárias de automóvel, como caronas, através de uma câmera instalada no automóvel utilizado por eles. Dessa maneira, tanto o próprio passageiro quanto o pesquisador puderam experimentar o ato de "mover-se" juntamente com aquilo que é móvel (no caso, o automóvel), o que neste caso em particular permitiu ao pesquisador estudar não apenas o tornar-se móvel, mas, já que o objeto do estudo eram os passageiros e não os motoristas, também o tornar-se imóvel.

$\mathrm{O}$ interesse aqui era entender como as pessoas constroem, através da prática de se locomover via automóvel no dia a dia (por exemplo, para o trabalho e de volta para casa), suas noções sobre lugar, espaço e subjetividade e, em especial, quais fazeres, obrigações e responsabilidades são atribuídos àquele que é "apenas” o passageiro e não o motorista - ou seja, aquele que não produz ele mesmo o movimento, experimentando-o e vivenciando-o como o carona, mas movimentando-se mesmo assim. Por sua vez, essa técnica de pesquisa permitiu a Laurier "mover-se", ainda que indiretamente, pois sua compreensão acerca dos significados produzidos pelo e através do movimento foi construída exatamente pela possibilidade de vivenciar, junto com o carona, através das gravações da câmera, esse mesmo movimento.

Com essa abordagem, o que o pesquisador buscava era obter informações mais ricas e detalhadas sobre o movimento, a mobilidade e o "mover-se" exatamente pelo ato de não estar ali (como mais um passageiro); esse distanciamento físico foi o que permitiu o distanciamento analítico necessário para perceber determinadas coisas que, tanto para o carona quanto para o motorista, pareciam óbvias. Dessa forma, foi construída uma "presença ausente" que, possibilitada pelos dispositivos de gravação utilizados pelos participantes da pesquisa, fez com que as práticas concretas de "ser passageiro" vivenciadas e produzidas pelos indivíduos fossem realizadas e capturadas ao vivo. 
Reforçamos, porém, que o objetivo principal do "mover-se" junto com aquilo que se move não é, nem o foi nesse caso, apenas trazer de volta dados que sirvam à análise de algum especialista positivista. Pelo contrário, o objetivo é o de fomentar a paciência necessária para revelar, analiticamente, os processos sociais e materiais do “tornar-se" (através do "mover-se”), demonstrando assim como, concretamente, se produzem realidades sociomateriais e subjetividades específicas por meio das práticas mundanas e cotidianas de movimento, assim como das especificidades, nesse caso particular, do "ser passageiro" e/ou de dirigir.

Metodologias semelhantes foram usadas, por exemplo, em estudos sobre documentos e arquivos históricos contendo relatos de experiências passadas de dirigir automóveis (e outros veículos); também nesses casos uma orientação analítica explicitamente voltada para aquilo que se movia, e para a mobilidade em si mesma, permitiu expandir a sensibilidade dos pesquisadores quanto à performatividade do movimento, facilitando assim uma compreensão mais aprofundada, e uma descrição mais densa, de como presentes, passados e futuros estavam (e poderiam estar) conectados através do movimento e da mobilidade (Merriman, 2013). Ainda outro exemplo vem de um estudo sobre a difusão e a circulação de cartões-postais em finais do século XIX; uma pesquisa utilizando métodos diversos, desde a etnografia histórica daquela cultura material (os próprios cartões, cujos movimentos os pesquisadores procuravam "seguir") até a análise de texto, permitiu revelar os ritmos peculiares daquelas trocas (Gillen e Hall, 2011, p. 34). A partir da análise de como se davam as trocas e movimentos de cartões e pessoas, os pesquisadores puderam, então, construir uma interpretação que relacionava trocas passadas de objetos e certas mobilidades pessoais por elas facilitadas (ou imaginadas), por um lado, com a emergência e criatividade de toda uma nova tecnologia de comunicação (os próprios postais), por outro.

Vale mencionar, por fim, que em nenhum desses exemplos estamos tratando apenas de métodos de coleta de dados. Qualquer que seja o uso que se faz de noções como "mover-se”, “tornar-se" (através do movimento), ser "móvel”, ou “movimento", e qualquer que seja o tipo de movimento vivenciado pelo pesquisador (movimento “direto", nos casos em que pesquisador e pesquisado se movem, ou "indireto", quando só os pesquisados se movem fisicamente, enquanto os pesquisadores vivenciam tal movimento de forma indireta, pelos dados coletados), todos os exemplos se referem a métodos que são "móveis" tanto em termos da coleta dos dados quanto de sua análise. No caso de Laurier (2010), seus métodos de coleta são móveis por definição, uma vez que é a câmera em movimento que acompanha o sujeito em movimento no automóvel em movimento e é assim que se coletam os dados. Mas sua metodologia de análise também é móvel, pois o que ele procura analisar é a própria produção do 
sujeito em movimento e, portanto, do próprio ato de "mover-se". Além disso, ao vivenciar tal movimento, indiretamente, pela observação e análise daquilo que a câmera registrou, refazendo assim as direções e trajetos que os participantes de sua pesquisa seguiram, a análise depende da possibilidade de o pesquisador experimentar tal mobilidade, mesmo que de forma indireta.

\section{Mover-se e o movimento}

As metodologias que descrevemos acima concebem e utilizam movimentações diversas que podem ser literais, indiretas ou analíticas. Todas estas são, por sua vez, usadas para permitir a apreensão de um processo que é, na verdade um "tornar-se" que, quase por definição (sendo ele produzido pelo movimento de coisas, seres e outros processos), é móvel. Entendemos por este “tornar-se (móvel)” os modos pelos quais lugares, espaços e subjetividades são produzidos pelas práticas vividas dos indivíduos, sejam elas móveis ou imóveis. Trata-se, portanto, de um "mover-se" como método. E este "mover-se" como método pode se dar em várias escalas ao mesmo tempo: podemos, assim, chamá-lo de multiescalar. É um método, então, que se preocupa com as realidades produzidas por movimentos que se dão em diferentes escalas. Os movimentos explorados por esse tipo de método podem ir desde microinterações entre os passageiros de um automóvel até os efeitos planetários de emissões de $\mathrm{CO}_{2}$.

As escalas dos movimentos que estudamos, porém, não precisam ser apenas as dos seres humanos, ou das sociedades onde eles estão inseridos. Alguns autores já vêm defendendo a necessidade de uma perspectiva mais ampla para entender o que acontece na Terra e com ela. O historiador Dipesh Chakrabarty (2009), por exemplo, foi um dos primeiros a usar o termo "antropoceno", entendido como a era geológica atual, dominada pela ação humana e seus efeitos sobre a Terra, para pensar as relações entre história, sociedade e a escala geológica do mundo físico. E Bruno Latour, há tempos interessado no entrelaçamento de atores humanos, não humanos e tecnológicos e na ideia de agência de seres e objetos não humanos, vem se utilizando do termo "Gaia” para se referir à Terra como sendo mais do que apenas o planeta que serve de habitat aos seres humanos, e sim como uma quase entidade que, conectada aos seres humanos, é capaz de sentir suas ações e os efeitos negativos das mesmas. Para Latour (2017), esta é uma forma de se pensarem processos como, por exemplo, a mudança climática. Em ambas as abordagens, a distinção entre o mundo físico (dos processos físico-químicos e geológicos que se dão em escalas macro), o mundo dos seres vivos e o mundo tecnológico (produzido por seres humanos) é menos importante do que perceber as conexões entre essas escalas. 
Partindo desse mesmo tipo de compreensão sobre a multiplicidade de escalas de análise para entender as mobilidades, e dialogando com a noção de antropoceno e com Latour, o sociólogo Bronislaw Szerszynski (2016) desenvolveu um estudo sobre nada menos do que as mobilidades planetárias: sua intenção era compreender como os planetas (em especial, o nosso) se movem. Para tanto, foi preciso "mover-se" através de uma lista impressionantemente abrangente de pesquisas e estudos nas áreas de física, biologia, paleontologia e sociologia ambiental, os quais Szerszynski analisou em detalhe até conseguir traçar aquilo que chamou, numa apta porém complexa formulação, de "um tornar-se planetário sublunar muito-longe-do-equilíbrio" (Idem). Este “tornar-se planetário", tão complexo e de nome um tanto pomposo, sugere Szerszynski, é exatamente o processo que produz as nossas realidades através dos diferentes movimentos que ocorrem nas diferentes escalas (Idem).

Primeiramente temos, diz Szerszynski, os movimentos e as escalas menores: as que se referem, por exemplo, às micropartículas que circulam na Terra e entre os seres vivos. A seguir, temos escalas um pouco maiores: as de movimentos como os dos animais. Depois, temos escalas ainda um pouco maiores: as das mobilidades antropogênicas tecnologicamente aumentadas com as quais temos tanta familiaridade hoje. E, finalmente, temos as escalas maiores de todas, em que esse "tornar-se planetário sublunar" se produz e se manifesta pelas correntes de jato planetárias e pelos vórtices oceânicos, bem como pelas mobilidades entre os planetas. Dessa maneira criativa, totalmente transdisciplinar, e móvel por definição, Szerszynski (Idem) conseguiu demonstrar e analisar as conexões entre essas diferentes escalas, seja no âmbito de vidas vividas (por pessoas e animais), seja nos processos geofísicos e nas lógicas interplanetárias, encontrando nessa metodologia um modo de explicar como a Terra se produz e organiza a si mesma.

O trabalho de Szerszynski (Idem) é, sem dúvida, instigante, e sugere caminhos promissores para expandirmos tanto o paradigma das novas mobilidades quanto os chamados métodos móveis na direção de novas escalas de análise. Se partirmos do princípio de que "a realidade é movimento", e se quisermos ampliar a noção de "realidade" para incluir, como o fez Szerszynski (Idem), movimentos geofísicos de, e entre, planetas, o próximo passo certamente seria, como ele o fez, ampliar a noção de métodos móveis. Incorporando tantas disciplinas quantas forem necessárias - das humanidades e ciências sociais às ciências biológicas, físicas e geofísicas -, é possível "movermo-nos junto" com nossos objetos de pesquisa, tanto na coleta quanto na análise dos dados, trafegando por escalas que vão do micro ao macro, seguindo o movimento por onde quer que ele esteja produzindo suas realidades específicas.

Há, porém, uma outra maneira de expandirmos o paradigma das novas mobilidades e os métodos móveis que, diferentemente de Szerszynski (Idem), não busca 
olhar para escalas diferentes das mobilidades e sim para seus efeitos e possibilidades políticas, éticas, epistêmicas e ontológicas. Por um lado, como discutimos até agora, temos aqueles estudos que buscam enfocar, empiricamente, a produção prática, concreta e mundana das ordens sociomateriais específicas e dos lugares, espaços e subjetividades que estão em movimento em diferentes escalas. Por outro lado, porém, seria importante avançarmos os métodos móveis na direção de um tipo de reflexão com motivações políticas mais explícitas: estudos, teóricos e empíricos, que dessem conta das diversas ontologias, éticas, moralidades, e epistemologias em jogo em torno desse "tornar-se móvel" em suas várias manifestações.

Com o avanço dos métodos móveis que vimos discutindo neste artigo, e em especial dado o estado atual do mundo contemporâneo - cada vez mais marcado por radicalismos, essencialismos, e i- e a-moralidades -, a politização dos métodos móveis tornou-se tanto possível quanto necessária. Tais considerações não são apenas de cunho metodológico ou teórico, obviamente. São também pessoais, sociais e políticas. Esse tipo de "chamado às armas" para que se produzam ontologias ético-epistêmicas de pesquisa mais "circunspectas", políticas, e voltadas para compreender as lógicas de poder e dominação intrínsecas a tantas dessas mobilidades não é, com certeza, novo. E o "chamado às armas" pode ser atendido tanto por aquelas e aqueles interessados nas práticas concretas de sujeitos concretos, quanto por quem, como Szerszynski (2016) e outros, se interessa por mobilidades em escalas maiores, globais ou mesmo planetárias e interplanetárias.

Tal foi o caso de um livro publicado já em 2007, há mais de uma década portanto, por Karen Barad, hoje professora de estudos feministas, filosofia e história da consciência na Universidade de Califórnia em Santa Cruz (Estados Unidos), originalmente professora universitária de física com doutorado em física teórica das partículas e teoria quântica. Abordando mobilidades as mais distantes possíveis das realidades materiais, sociais, e políticas dos indivíduos - os movimentos das partículas estudadas pela física quântica e os entrelaçamentos entre os mundos físico e social -, Barad (2007) retrabalha as teorias feministas, em especial as de Judith Butler sobre performatividade, bem como outras vertentes da teoria crítica e pós-estruturalista. Sua intenção é (re)construir toda uma teoria sobre espaço, tempo, matéria, causalidade, agência e subjetividade que conecte o mundo material (físico) e o mundo social das pessoas.

No que Barad (Idem) chamou de uma "teoria do realismo agencial", o mundo é compreendido como algo que se produz a partir dos encontros entre as agências sociais e naturais (ou seja, entre o mundo social e o físico), através de um dinamismo infindável (e "móvel" por definição) que deve ser o foco de toda análise, seja ela voltada para o mundo social ou para o físico. Essa construção teórica abre espaço também para 
considerações metodológicas sobre o que observar e como observar quando se busca compreender as interações e mobilidades que constituem tal dinamismo. Em vez de postular "natureza" (o mundo físico) e "cultura" (o mundo social) como pertencentes a diferentes ordens e escalas de grandeza, a teoria de Barad enfatiza exatamente o dinamismo das interações entre os dois eixos. Essas interações, argumenta Barad, são exatamente aquilo que está (re)constituindo, de maneira constante, um e outro eixo e as relações entre ambos. Como corolário, Barad (Idem) postulou assim que toda ciência do mundo físico é necessariamente política, pois o eixo política-sociedade-cultura não está "fora” do eixo matéria-tempo-espaço; pelo contrário, ambos os eixos estão interligados e precisam ser analisados em suas inter-relações - o mundo é um só e deve ser analisado como tal, através da observação dos movimentos dinâmicos e incessantes entre as agências sociais e as agências físicas (Ibidem).

Assim como Barad, outros pesquisadores interessados em compreender como realidades concretas e seus efeitos sobre as pessoas são construídos, ora pelo movimento, ora por seus opostos - bloqueios ao movimento, ou stasis (falta de movimento), em diferentes escalas -, também vêm se "locomovendo" através das fronteiras disciplinares. Muitos acabam "movendo-se" de vez para outras disciplinas, ou mesmo para fora das "disciplinas" acadêmicas tradicionalmente concebidas. Isso porque realmente entender os múltiplos contextos concretos e complexos nos quais os seres humanos vivem suas vidas, de modos multiescalares e móveis, tem requerido cada vez mais criatividade, experimentação, transdisciplinaridade e crítica da parte de quem pesquisa.

Se, em Barad (2007), encontramos uma física teórica estudando política, agência e feminismo, temos no trabalho da artista Jen Southern (2012) sobre "comobilidade" um outro exemplo significativo de até onde podemos chegar na concepção e utilização de métodos móveis. O interesse de Southern (Idem) era compreender as práticas de resgate de alpinistas nas montanhas e suas mobilidades, mas tanto o conceito de mobilidades, quanto seus métodos de estudo foram ampliados de tal forma que o trabalho se transformou quase em um tratado metodológico sobre tais assuntos. Essa expansão do estudo das mobilidades começou quando ela resolveu mover sua pesquisa sobre sistemas de posicionamento geográfico (GPS) para o âmbito da sociologia, o que lhe permitiu traçar novos caminhos, retornos e desvios teóricos e metodológicos que possibilitaram novos pontos de vista sobre os fenômenos pesquisados, numa mistura de perspectivas disciplinares particularmente inventiva e analiticamente relevante e inovadora.

Suas investigações sobre práticas de resgate nas montanhas se transformaram num estudo sobre o que ela chamou de um "novo sentido de comobilidade, de ser e estar móvel com outros a distância” (Idem, p. 75). Essas investigações, por sua vez, 


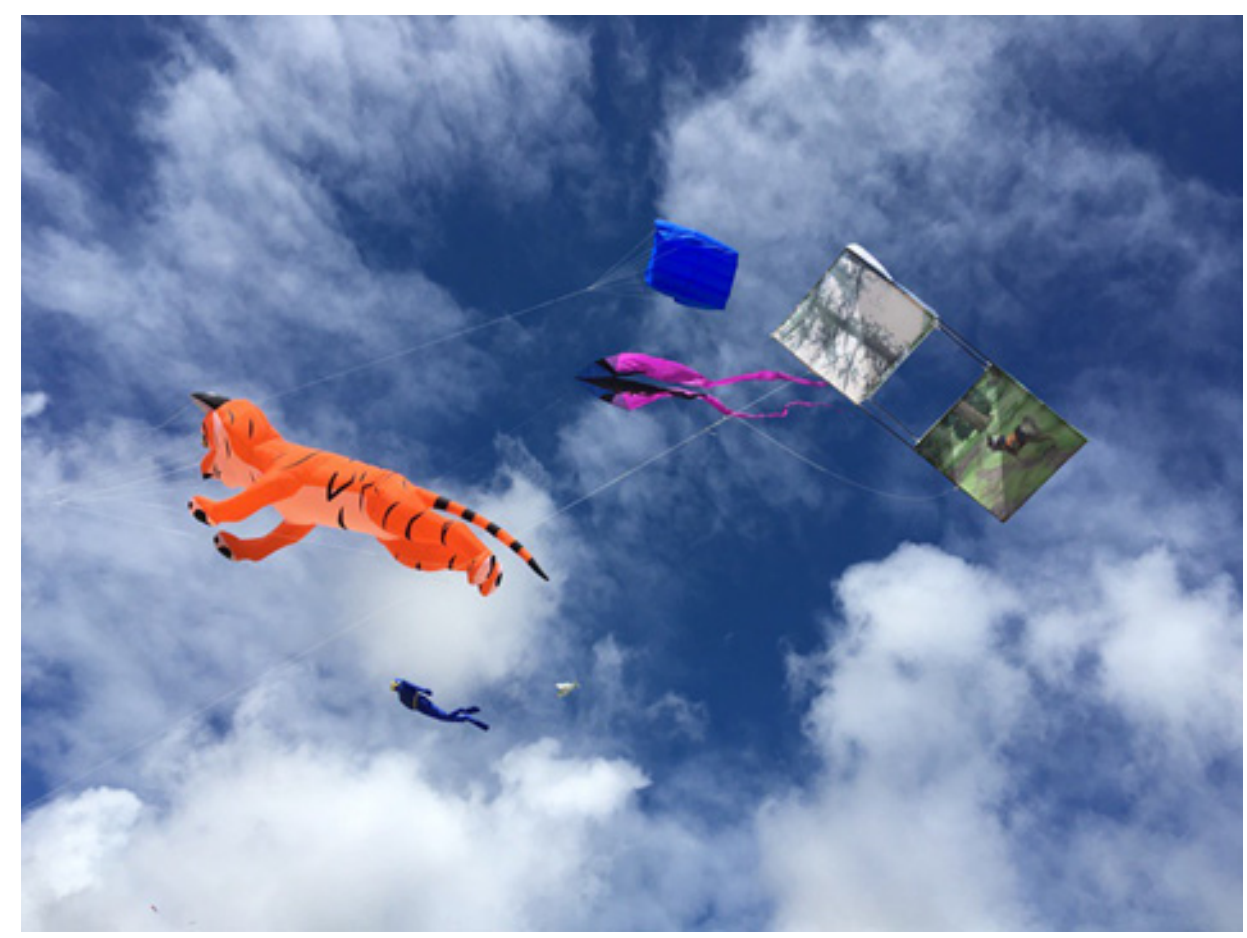

Figura 1: Fotografia de Jen Southern. Neste trabalho, que é ao mesmo tempo artístico e analítico, Southern fez uma montagem unindo imagens de cães de resgate e as pipas no céu; seu objetivo era explorar as conexões entre satélites de GPS, coordenadas espaciais e práticas de resgate nas montanhas.

se deram de uma forma especialmente criativa e "diferente": partindo, reflexivamente, de explorações literárias sobre Antoine de Saint-Exupéry e sua obra, ela foi se engajando, gradualmente, nas seguintes atividades: aprender a voar, interagir com pilotos, estudar e interagir com renas e seus pastores, desenvolver um "aplicativo de comobilidade", estudar sua aplicação e como o aplicativo podia ser (e era) usado para organizar a vida cotidiana, trabalhar (via observação participante), primeiro com cães de resgate e seus treinadores nas montanhas e depois com pessoas que conduziam buscas, também nas montanhas, com o auxílio de pipas (Figura 1).

O fato de alguns aparelhos, como os celulares, já conseguirem usar e compartilhar dados sobre localização geográfica através de redes de dados, através do espaço, e entre pessoas, está constituindo uma nova percepção - que Southern chama de "comobilidade", ou "mover-se junto com os outros [mesmo que] a distância". "Estranhas" e "dispersas" como possam parecer tais atividades, a autora consegue nos mostrar, por meio dessas investigações múltiplas e multissituadas, precisamente o quanto essas práticas de posicionamento, e as "comobilidades" que lhes davam forma, estavam entrelaçadas e misturadas. Foi exatamente seu olhar curioso sobre essas interações 
que lhe permitiu revelar quão profundo é, no caso estudado, o entrelaçamento entre o social e o técnico, o aqui e o lá, e múltiplos presentes, passados e futuros.

\section{Mover-se e comover-se}

Mas o que acontece quando, ao pesquisar movimentos, os pesquisadores "se comovem", ou seja, são afetados emocionalmente pelas atmosferas, afetos e injustiças que encontram em seu caminho? Uma reação, obviamente, poderia ser a de buscar analisar "racional" e "objetivamente" o próprio sentimento de comoção assim produzido, e as realidades que o provocaram. Outra reação possível, porém, e mais antenada com o novo paradigma das mobilidades, geraria modos de análise mais emocionais e criativos: os pesquisadores poderiam usar não só o movimento ou o "mover-se", mas o próprio ato de "comover-se" como método, inserindo seu próprio corpo nos contextos pesquisados e utilizando-o como, nas palavras de Sheller e Urry (2006, p. 216), "um veículo afetivo através do qual nós sentimos o lugar e o movimento e construímos geografias emocionais".

Um dos exemplos mais dramáticos desse potencial dos métodos móveis para comover vem de um estudo sobre assistentes sociais e casos de maus-tratos a crianças conduzido por Harry Ferguson. Seu objetivo era estudar etnograficamente as práticas de assistentes sociais, "seguindo" essas pessoas durante seu trabalho cotidiano, o que, nesse caso, envolvia fazer visitas a domicílios onde havia suspeitas (ou acusações formais) de maus-tratos a crianças. Essa “etnografia móvel” gerou uma descrição densa daquilo que o autor chamou de "cenas comoventes da assistência social" (Ferguson, 2011, pp. 78-80).

Sentindo-se, ele mesmo, comovido pelo caso de um menino de dezessete meses que havia morrido em Londres em 2007, em decorrência de mais de cinquenta ferimentos sofridos em sua própria casa enquanto seus cuidadores estavam sob a supervisão de assistentes sociais do Estado, Ferguson poderia ter se limitado a denunciar as inadequações do trabalho dos assistentes, culpando-os pelos resultados negativos (a impossibilidade de proteger as crianças). Ou então, ele poderia ter sublimado suas emoções e se limitado a descrever as mobilidades - de assistentes, responsáveis e da mídia - envolvidas no caso. Ferguson não fez uma coisa, nem outra: seu estudo foi construído contrastando, de um lado, a análise dos modos pelos quais se culpam os assistentes sociais quando não conseguem avaliar corretamente as situações de maus-tratos que encontram e, de outro, uma etnografia comovente das emoções vivenciadas pelos assistentes durante as visitas às famílias; são essas emoções como ansiedade e medo que, conclui Ferguson, minam a capacidade de avaliação dessas pessoas sobre os domicílios e famílias que visitam (Idem). 
Em seu relato etnográfico, Ferguson descreve minuciosamente o ato de acompanhar as visitas dos assistentes dentro e fora dos domicílios, revelando os inúmeros obstáculos que os responsáveis impunham aos assistentes durante as visitas na tentativa de ocultar suas próprias práticas violentas. A análise de Ferguson não enfocou apenas as práticas de mobilidade em si mesmas (entrar e sair das casas e quartos, andar pelos ambientes da casa etc.); seu olhar (e comovimento, já que ele acompanhava os assistentes nas visitas) se voltou também para as práticas que tentavam coibir movimentos e assim gerar emoções negativas: corpos humanos e animais que ameaçavam os assistentes que tentassem aproximar-se, pilhas de roupas sujas colocadas estrategicamente nas portas dos quartos para dificultar a entrada, manchas de chocolate nos rostos das crianças para esconder machucados, e assim por diante (Idem).

Tudo isso, diz Ferguson, dificultava as avaliações dos assistentes, impedindo-os de enxergarem realmente o que se passava naqueles lares. Metodologicamente, conclui ele, o "mover-se com" os sujeitos pesquisados não produz apenas dados sobre os movimentos em si mesmos. Sim, o pesquisador ou pesquisadora pode e deve acompanhar e seguir os sujeitos que pesquisa; de preferência, utilizando-se de metodologias etnográficas de "estar junto", "ir junto" e "voltar junto", seguindo os sujeitos, fisicamente, enquanto esses movem seus corpos pelo espaço. Mas esse acompanhamento das mobilidades não precisa ter como objeto a própria mobilidade: no caso desse estudo, o que interessava a Ferguson não eram as práticas de mobilidade dos assistentes sociais, e sim as relações sociais e políticas, e as políticas de visibilidade, que se construíam (ou deixavam de ser construídas pela ação de sujeitos que não queriam ser olhados) através dessas mobilidades.

E mais: o que esse tipo de etnografia móvel consegue apreender, através da análise do movimento (e do não movimento), são as emoções, afetos e sentimentos assim produzidos, pelas, através, e apesar das trajetórias dos corpos das pessoas e de outros corpos, objetos, e demais barreiras impostas a essas trajetórias. Ao "mover-se com" assistentes sociais e outras categorias profissionais, argumenta Ferguson, a pesquisa em mobilidades consegue revelar certas geografias emocionais que, claramente, impactam as práticas profissionais. Levando ainda mais adiante o raciocínio, Ferguson sugere que tais análises podem e devem ser utilizadas para questionar práticas profissionais correntes e demandar mudanças - por exemplo, lutando para que assistentes sociais recebam mais apoio para viabilizar suas mobilidades físicas e mais apoio também para lidar com os desafios emocionais de sua prática (Idem).

Outro uso que se pode fazer dessa relação entre "mover-se" e "comover-se", ou seja, entre movimento e emoção, é abordar os métodos móveis de uma forma mais metafórica. Tal é o caso, por exemplo, de um estudo de Sara Ahmed (2004) que utilizou métodos discursivos, baseados em análise de texto, para "seguir" fenômenos 
relacionados a afeto e emoção. Mais especificamente, seu foco eram os modos como determinadas emoções - como dor, ódio, medo, nojo, vergonha, amor e emoções ligadas ao feminismo e às subjetividades queer - circulam nas esferas públicas virtuais e semivirtuais da sociedade. Em seu texto, Ahmed descreve seus esforços metodológicos para acompanhar ("seguir") o que se dizia sobre tais emoções em sites na internet, relatórios do governo, discursos proferidos por políticos e artigos jornalísticos. Foi através de sua própria movimentação por esses diferentes meios e discursos que Ahmed conseguiu apreender como se manifestavam e eram explicitadas aquelas emoções, como eram produzidas e nomeadas, quem as produzia e a quem eram destinadas, e a quem emocionavam.

Sua proposta era, então, "mover-se" juntamente com a circulação daquelas emoções, método que Ahmed justificou pelo fato de que "as emoções, afinal de contas, estão em movimento, mesmo que elas não se movam de maneira simples entre nós" (Idem, p. 11). Com esse acompanhar dos movimentos das emoções construídas e circuladas por aqueles meios, Ahmed buscou delinear as facetas do que ela chamou de uma "política cultural das emoções". Seu objetivo era mostrar que as palavras usadas para referenciar emoções e sentimentos circulam, e as emoções circulam junto com elas; é assim que se engendram efeitos: elas se movem, "grudam" "escorregam" e, por esses processos, "criam as próprias superfícies, fronteiras e distinções" que conectam, e dividem, as sociedades" (Idem, p. 15). Este seria, por exemplo, o caso do ódio que, segundo Ahmed, opera através de processos que "grudam 'imagens de ódio' umas às outras e a pessoas e grupos específicos, transformando-os, todos, numa ameaça comum" - como é o caso, hoje, dos discursos contra refugiados e imigração, nos quais pessoas, grupos e processos diferentes são verbalmente construídos como se fossem uma coisa só, passível de ódio (Idem).

Assim, com esse tipo de metodologia, o que Ahmed conseguiu mostrar foi que emoções como medo, raiva e vergonha são, sempre, políticas; sua força política se produz, exatamente, através desses efeitos de circulação. E "comover-se", aqui, adquire um sentido diferente do exemplo anterior. Aqui, o mover-se através e junto com os movimentos das emoções produzidas e explicitadas por tais efeitos discursivos leva a pesquisadora - e, esperamos, também seus leitores - a compreender mais profundamente os efeitos deletérios das palavras usadas para criar e significar ódios, desprezos e preconceitos, e os processos mesmos pelos quais tais emoções são não só manifestas, mas também "atreladas" a certos grupos e figuras humanas via esses processos simbólico-metafóricos que são nada mais do que construções imaginadas sobre o valor relativo de indivíduos, grupos e até sociedades inteiras. 
Mover-se por impulso

Não devemos, agora, perder o impulso que ganhamos na seção anterior: métodos móveis permitem-nos seguir os movimentos, mesmo que metafóricos, de coisas e pessoas, mas também de ideias e emoções. Revelando os processos de produção, explicitação e disseminação desses movimentos, também podemos expor sua força política, seja ela negativa (como no estudo de Ahmed), ou positiva (como em Ferguson). Pensando dessa maneira, o que aprendemos com esse tipo de pesquisa que nos "comove" pode ser mobilizado e inspirar alguns de nós a demandar mudanças sociais e políticas - precisamente como o sugeriu Ferguson.

"Mover-se" como método e como metodologia, tal como vimos discutindo, e em particular a possibilidade de "comoção" gerada pelos movimentos estudados, pode gerar o impulso necessário para que os indivíduos se engajem em novas formas de intervenção concreta e ação coletiva. Isso, às vezes, pode levar alguns pesquisadores a, literalmente, "mover-se para dentro" dos problemas. Foi exatamente isso o que aconteceu no caso da pesquisa de Büscher, Hemment, Coulton e Mogensen sobre o uso de tecnologias de informação para facilitar o atendimento às vítimas em casos de risco, crise e desastres ambientais e sociais (Büscher et al., 2011). Trabalhando com metodologias interativas e experimentais, a pesquisa tinha um caráter eminentemente prático, com a construção de protótipos de novas tecnologias de atendimento a vítimas de desastres e sua aplicação em cenários experimentais para monitorar efeitos e efetividade. Ao estudar problemas relativos aos modos de governança dos desastres, às estratégias tecnológicas de monitoramento de movimentos e processos, assim como os impactos concretos sobre os seres humanos afetados - seja os que conduziam os resgates, seja os resgatados -, a equipe "mergulhou" de tal forma nas questões de pesquisas que acabou por pensar tais problemas "de dentro para fora”. Os pesquisadores se viram emocionalmente envolvidos naquelas questões que diziam respeito à vida e à saúde de pessoas reais vitimizadas por desastres e dependentes de serviços de resgate (Idem).

Nesse caso, o "mover-se para dentro" dos problemas não fez apenas com que os pesquisadores se emocionassem e comovessem com histórias de desastres e resgates: levou-os a desenvolverem uma abordagem de pesquisa mais voltada para a intervenção. Isso significou, na prática, envolver-se no próprio design das tecnologias para torná-las mais adequadas e experimentar diferentes protótipos. Assim conseguiram enxergar algumas consequências não intencionais daquelas tecnologias e protótipos que teriam passado despercebidas de outra forma - como o fato de que os sistemas tecnológicos produzidos para ajudar cidadãos e funcionários em situações de crise acabavam por expandir a vigilância sobre os mesmos cidadãos. E o método permitiu 


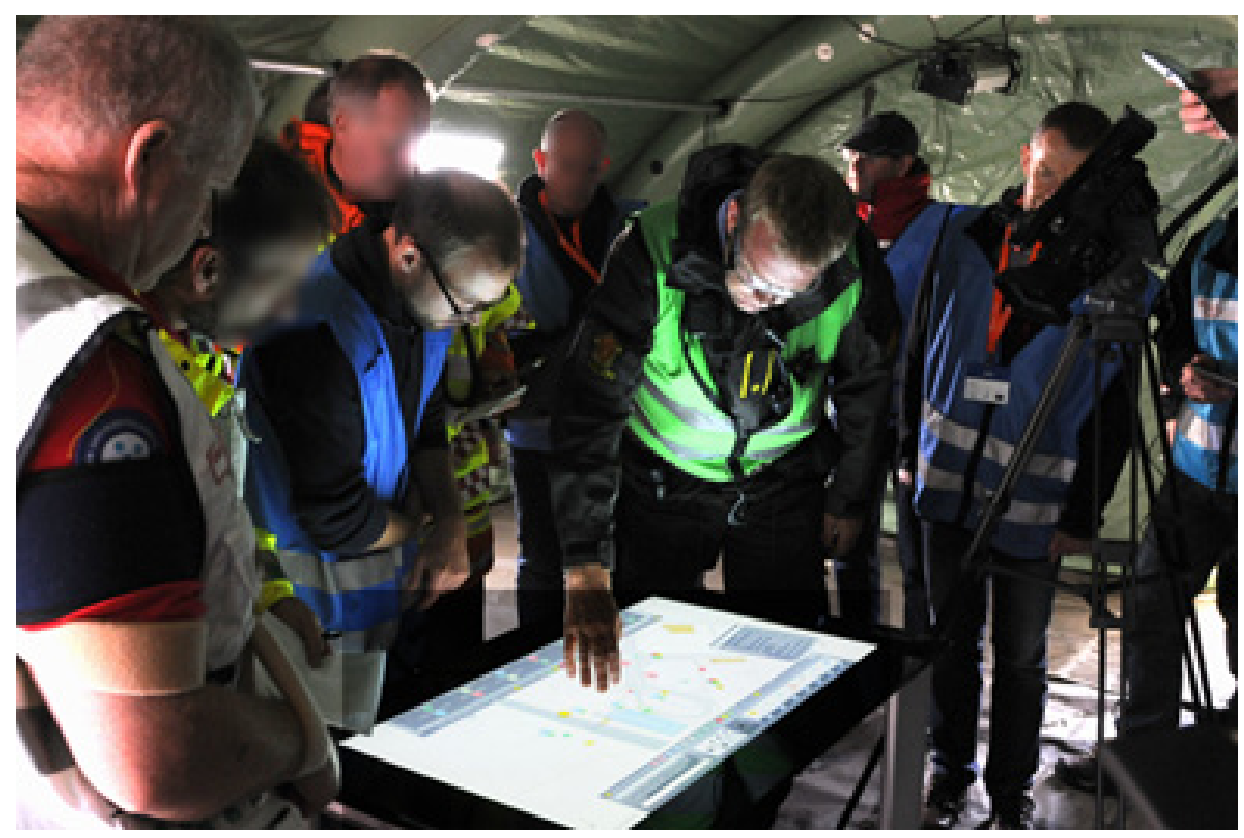

Figura 2: Experimentando os protótipos e descobrindo as consequências não intencionais das tecnologias de monitoramento utilizadas na governança do risco em casos de desastres. Fotografia de Monika Büscher.

aos pesquisadores não só perceberem essa consequência não intencional, mas também intervirem criativa e criticamente sobre a mesma - propondo, construindo e experimentando novos protótipos. A criatividade do método, nesse caso, veio exatamente dessa imersão dos pesquisadores "dentro" do problema pesquisado: trabalhando com protótipos e experimentando com possibilidades alternativas, o grupo conseguiu explorar, perceber, e se comover com aquelas consequências sobre as quais não se tinha ideia antes, colaborando em seguida na construção de alternativas viáveis (Figura 2).

\section{Conclusão}

Os métodos que aqui discutimos não são só recursos para possibilitar pesquisas: trabalhando no âmbito do novo paradigma das mobilidades, os casos que escolhemos apresentar neste artigo representam avanços importantes e pertinentes na direção de uma maior interação entre teoria e método no estudo de mobilidades diversas. Alguns trabalham com noções extremamente criativas do que sejam "movimento" e "mobilidades", como o estudo de Mesman na unidade neonatal, ou o de Ahmed sobre a produção política das emoções. Outros se utilizam de uma noção literal de "mover-se" e, mesmo que o pesquisador não se locomova ele mesmo durante a pesquisa, o foco metodológico e analítico recai sobre o movimento em si (como 
no trabalho de Laurier). Outros ainda enfatizam a necessidade de "comover-se" no âmbito das pesquisas sobre o "mover-se", como em Ferguson e na pesquisa do grupo de Büscher sobre governança tecnológica de risco e desastres.

Em todos esses casos, uma contribuição importante está em que esses estudos podem ajudar a (co)mover as pessoas, motivando-as a se tornarem mais respeitosas e responsáveis, mais interessadas no bem comum, mais apaixonadas pela busca de soluções coletivas, e mais abertas a formas múltiplas e divergentes de expertises, interesses e motivações. Assim, o uso desses métodos móveis, ao exigir que desenvolvamos novas habilidades analíticas para melhor conseguir perceber tudo aquilo que é emergente e desconhecido - como os efeitos negativos das tecnologias estudadas pelo grupo de Büscher, ou os processos de mudança em escala planetária discutidos por Szerszynski e Badar -, também abre caminhos para se questionarem poderes e repensar noções de justiça social e responsabilidades. Sob este ponto de vista, os métodos móveis se prestam bem a uma sociologia pública atenta a tais questões (Sheller, 2015). Afinal, ao reconhecer toda realidade como intrinsecamente móvel, os métodos móveis nos forçam a levar esse reconhecimento até suas últimas consequências: sendo a realidade móvel, ela por definição não é imutável; portanto, as coisas poderiam ter sido, ser, e vir a ser diferentes - em outras palavras, elas podem ser transformadas. Afinal, se a realidade se faz através do movimento, ela pode ser, via movimento, refeita, repensada e modificada.

\section{Referências Bibliográficas}

Ahmed, Sara. (2004), The cultural politics of emotion. Londres, Routledge.

BARAD, Karen. (2007), Meeting the universe halfway. Durham, NC, Duke University Press.

Bergson, Henri. ([1919] 1960), Creative evolution. Londres, Macmillan.

Brown, Katrina \& SPINnEY, Justin. (2009), “Catching a glimpse: the value of video in evoking, understanding and representing the practice of cycling". In: Fincham, Ben et al. (orgs.). Mobile methodologies. Londres, Palgrave MacMillan uK, pp. 130-151.

Büscher, Monika et al. (2011), "Mobile, experimental, public”. In: BüsCher, Monika et al. (orgs.). Mobile methods. Londres, Routledge, pp. 119-137.

BüsCHER, Monika et al. (orgs.). (2011), Mobile methods. Londres, Routledge.

Chakrabarty, Dipesh. (2009), “The climate of history”. Critical Inquiry, 35 (2): 197-222.

Ferguson, Harry. (2011), "Mobilities of welfare: the case of social work". In: BüsChER, Monika et al. (orgs.). Mobile methods. Londres, Routledge, pp. 72-87.

Fincham, Ben et al. (orgs.). (2010), Mobile methodologies. Londres, Palgrave MacMillan. Gillen, Julia \& Hall, Nigel. (2011), “Any mermaids? Early postcard mobilities”. In: BüsCHER, Monika et al. (orgs.). Mobile methods. Londres, Routledge, pp. 20-35. 
Hannam, Kevin et al. (2006), "Editorial: Mobilities, Immobilities and Moorings". Mobilities, $1(1): 1-22$.

Latour, Bruno. (2017), Facing Gaia: eight lectures on the new climatic regime. Londres, Polity.

LAURIER, Eric. (2010), "Being there/seeing there: recording and analyzing life in the car". In: Fincham, Ben et al. (orgs.). Mobile methodologies. Londres, Palgrave MacMillan, pp. 103-117.

Merriman, Peter. (2013), "Rethinking mobile methods. Mobilities, 9 (2): 167-187.

Mol, Annemarie \& Mesman, Jessica. (1996), "Neonatal food and the politics of theory: Some questions of method”. Social Studies of Science, 26 (2): 419-444.

SHELlER, Mimi. (2015), "Vital methodologies: live methods, mobile art, and research-creation". In: VANnINI, Phillip (org.). Non-Representational methodologies: re-envisioning research methods. Londres, Routledge, pp. 130-145.

Sheller, Mimi. \& Urry, John. (2006), “The new mobilities paradigm”. Environment and Planning A, 38 (2): 207-226.

Southern, Jen. (2012), "Comobility: how proximity and distance travel together in locative media”. Canadian Journal for Communications, 37 (1): 75-91.

SZERSZYNSKI, Bronislaw. (2016), "Planetary mobilities: movement, memory and emergence in the body of the Earth”. Disponível em http://wp.lancs.ac.uk/bronislaw-szerszynski/ files/2016/02/Szerszynski-Planetary-mobilities.pdf, consultado em 1/1/2018. 


\section{Resumo}

\section{Métodos móveis}

Este artigo discute os chamados métodos móveis em sua relação com o novo paradigma das mobilidades e com o papel central do movimento na produção de realidades e mundos sociais e sociofísicos. Em vez de oferecer um "manual de pesquisa", o artigo apresenta algumas pesquisas emblemáticas no uso desses métodos e como elas avançam nossa compreensão sobre as mobilidades em seus aspectos sociais, políticos, epistemológicos e emocionais. Os exemplos estão agrupados em torno de eixos temáticos: (1) mover-se e tornar-se, (2) mover-se e o movimento, (3) mover-se e comover-se, e (4) mover-se por impulso. Concluímos sugerindo que os métodos móveis podem ser instrumentais para uma "sociologia pública” voltada para a mudança social. Palavras-chave: Metodologia; Mobilidades; Movimento; Emoções; Política.

\section{Abstract}

\section{Mobile methods}

This article focuses on mobile methods and their relationship to the new mobilities paradigm and the central role of movement in the production of realities and social and socio-physical worlds. Rather than to offer a "research manual", our goal is to present certain key examples in the use of such methods and to discuss how they may foster our understanding of mobilities in their social, political, epistemological, and emotional aspects. The examples are grouped around key themes: (1) moving and becoming, (2) moving and movement, (3) moving to be moved, and (4) moving with momentum. We conclude by suggesting that mobile methods can be instrumental in the making of a "public sociology" interested in producing social change.

Keywords: Methodology; Mobilities; Movement; Emotion; Politics.

Texto recebido em 9/1/2018 e aprovado em 16/1/2018.

DOI: $10.11606 / 0103-2070 . t s .2018 .142258$

MONIKA BÜSCHER é professora de sociologia e diretora do Centre for Mobilities Research, da Lancaster University, no Reino Unido.

Leticia Veloso é professora do Departamento de Sociologia e Doutorado em Sistemas de Gestão Sustentáveis, da Universidade Federal Fluminense. E-mail: lveloso.uff@gmail.com. 